\title{
Will Sub-Saharan Africa Meet the Millennium Development Goals and Does it Matter?
}

\author{
Donald L Sparks ${ }^{1, *}$ \\ ${ }^{1}$ Office of Fellowships, The Citadel, Charleston, SC 29409, United States \& International \\ Business and Law Program, Management Center Innsbruck, Austria \\ *Correspondence: Office of Fellowships, The Citadel, Charleston, SC 29409, United States \\ \& International Business and Law Program, Management Center Innsbruck, Austria \\ Tel: 1-843-953-5159_E-mail: sparksd@citadel.edu
}

Received: February 19, 2013 Accepted: March 6, 2013 Published: March 25, 2013

doi:10.5296/rae.v5i1.3281 URL: http://dx.doi.org/10.5296/rae.v5i1.3281

\begin{abstract}
In 2000 the largest gathering of world leaders in history met at the United Nations to endorse the Millennium Development Goals (MDGs) and these goals have received wide-spread attention since then. This paper examines these goals and also considers the larger issue of economic growth and development. For sub-Saharan Africa's economies to grow, we need to recognize the role and functions of the informal ruling sector and also acknowledge the incentives involved. Equally important perhaps, we need to rethink the development agenda: today that agenda is dictated by and large by the Western donors. In the future that agenda must be driven by the realities of the combination of the mix of informal and formal governing structures. If rulers continue to commit to meeting the objectives at the formal level while at the same time prioritize the demands of the informal sector then they will not be able to escape the poverty trap and underdevelopment nor move toward true, sustained economic and social development for all of their people. At the end of the day, what really matters is not if Africa reaches the Millennium Development Goals, since goals, while important in measuring welfare success, do not really address the more urgent need for stimulating productive and sustained economic growth that in the long term will translate into higher welfare.
\end{abstract}

Keywords: sub-Saharan Africa; millennium development goals; economic development; economic growth; formal sector; informal sector 


\section{Introduction}

In economics we learn about scarcity that leads to the choices we must make as individuals and as a society. By making any choice we are left with the opportunity cost of the value of the next best alternative forgone. While leaders anywhere must constantly make such choices, this paper argues that the range of choices is more limited in sub-Saharan Africa. Complicating these daunting social challenges is the type of governing structure, as in many states the formal and informal political orders overlap (this is an example of what is known in the literature as a patron-client relationship or neo-patrimonialism). This paper will examine some of these limitations and offer an explanation as to why no state in sub-Saharan Africa will meet all of the United Nations Millennium Development Goals (MDGs) by the 2015 deadline and suggest that it may not matter if the goals are not met.

\section{Meeting the Goals}

In 2000 the largest gathering of world leaders in history met at the United Nations to endorse the Millennium Development Goals (MDGs) and these goals have received wide-spread attention since then. Initially the goals were to be universal but now they are used at the regional level (and can be used at the country level). Viewed globally there has been significant progress over the past 13 years. For example, according to the UN's Millennium Development Goals Report 2012, extreme poverty is falling in every region and the poverty reduction target has been met; the world has also met the target of halving the proportion of people living without access to improved sources of water and has achieved parity in primary education between boys and girls, and the world is on track to achieve the target of halting and beginning to reverse the spread of tuberculosis. Indeed, it should be noted that as these goals are being met, at least in most areas of the world, there now plans for a "Post 2015 Development Agenda".

The MDGs were established to act as a motivator to increase development in poor countries and to act as a measure of performance. Here is where the problem begins: the way in which the measurements themselves were stated may have resulted in a bias against Africa's likelihood of achieving the goals. A number of studies (Easterly 2009, Attaran 2005, Clemens 2005, Vandemoortele 2007) argue the MDGs targets were essentially a set up (for reasons unclear) for the region to fail and in fact Africa has and is making significant progress in a number of areas.

Sub-Saharan Africa is highly unlikely likely to meet all of the MDGs(Note1): numerous reports from the World Bank, the UN, the World Economic Forum, the Blair Commission and many others all have said that Africa is behind in progress and will not meet the goals by the 2015 deadline. The World Bank's 2011 Global Monitoring Report indicates that sub-Saharan Africa has the largest amount of "progress insufficient to reach target if prevailing trends persist" (see Figure 1). However, if one examines the seven goals individually one can see that how the goals are measured can actually bias the conclusions. 


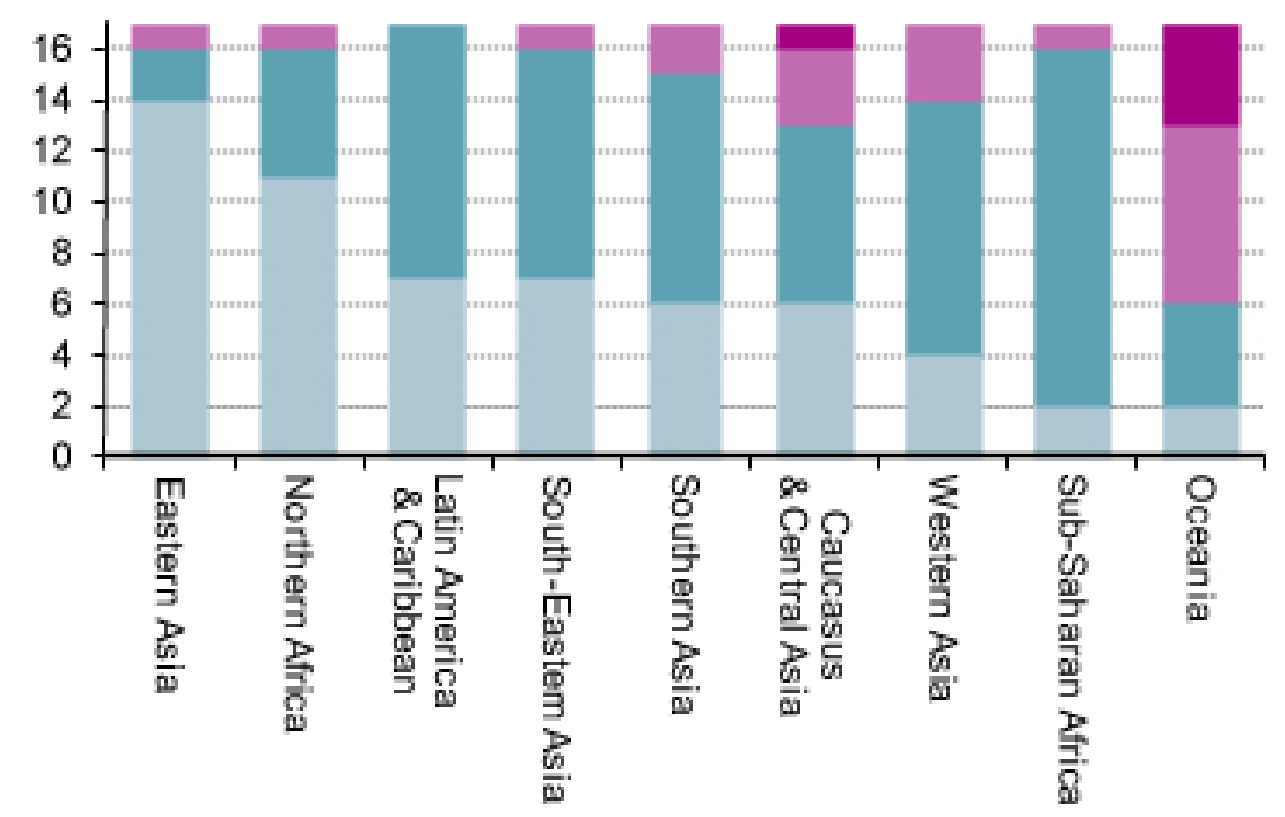

- Missing or insufficient data

n No progress or deterioration

- Progress insufficient to reach the target if prevailing trends persist

- Target already met or expected to be met by 2015

Figure 1: Progress Made Toward MDGs in Selected Indicators by Region, 2011

Source: UNCTAD secretariat calculations based on United Nations, Millennium Development Goals: 2011

Progress Chart.

Goal Number One: Halve, between 1990 and 2015, the proportion of people whose incomes is less than $\$ 1$ a day.

On average, sub-Saharan Africa has made progress in reducing poverty, at least in a relative sense: in $199057 \%$ of its population lived at or under $\$ 1$ per day, now it is $47.5 \%$. However, as Easterly correctly asked: which more desirable, for Latin America to halve its poverty rate from $10 \%$ to $5 \%$ or Africa to cut it from $50 \%$ to $35 \%$ ? (Easterly, 2009). The absolute change (and the percent of the population affected) would be three times greater in Africa than in Latin America, although the proportional cut is less. Because of its high poverty rate, Africa needs higher economic growth than other regions to reach the first MGD. And, as Easterly (2009) notes, “... a goal of reducing poverty rates places great value on growth that moves an individual from below to above the absolute poverty line, while it places zero value on growth that increases incomes of those who still remain below the poverty line."

In addition, one should consider economic growth rates: in 2007 the Africa Progress Panel suggested that the region needs an annual GDP growth rate of 7\%, up from its existing 5.4\% if it is to make "...substantial inroads into poverty reduction" (Clemens, 2007). In fact, an annual growth rate of 5.4\% in itself is impressive: should it last until 2015 it would be in the 
top 1/5 of GDP growth rates during the period 1965-2005 for all regions. To get to 7\% would put the rate in the top $10 \%$ of all growth rates during the same time. Indeed, the actual growth of 5.2\% between 2000-07 is the highest recorded for a seven-year period in Africa's history. It should be noted, however, that much of this growth has been driven by a commodity boom and is based on fragile underpinnings. Since Africa started out with the lowest per capita income it has the furthest to go and accordingly MDG goal number one is rated a failure.

Goal Number Two: Ensure that, by 2015, children everywhere, boys and girls alike, will be able to complete a full course in primary schooling.

This is an important goal for the region since $44 \%$ of the population is below the age of 15 and education is key to development. Today about $75 \%$ of the primary school aged children are enrolled in school. Here again the standards put Africa at a disadvantage. This goal is an absolute one, not a relative one, and as since Africa has the lowest primary enrollment of any region it has the furthest to go to meet the goal of $100 \%$ primary enrolment. Many countries in the region have made remarkable strides in increasing enrollments, yet again the region is rated as a failure. Had the goals been one of proportional increases then Africa would be rated as a success. Another important indicator might include literacy: the region's adult literacy rate has nearly doubled from $38 \%$ in 1980 to $65 \%$ today.

Nonetheless, with an ever-increasing number of children, to meet the growing demand for education, thousands of news school must be built, tens of thousands new teachers hired, increased funding for school lunches and more. Countries in the region (on average) currently spend about $\$ 160$ million annually on education, equal to $4.3 \%$ of its total budget (or $1.4 \%$ of GDP). It will need to double that amount in order to meet the needs listed above.

Goal Number Three: Eliminate gender disparity in primary and secondary education, preferably by 2005, and in all levels of education no later than 2015 .

Countries in the region are coming close to meeting this goal at the primary school level where the percentage of boys is $80.6 \%$ and girls $88.1 \%$. However, in secondary schools the percentage of boys is only $25 \%$ and girls $22 \%$. Here again is an absolute goal to attain $100 \%$ ratio of girls to boys. However, this goal is almost a re-statement of goal number 2, because if all children are in school the ratio is meaningless. In any case, the region is making strides in female to male primary enrollment in terms of percentage changes. Paradoxically, as Africa makes these strides it is still rated as a failure in achieving the $100 \%$ goal.

Goal Number Four: Reduce by two thirds, between 1990 and 2015, the under-five mortality rate.

Since 1960 Africa has shown improvement here, from child mortality declining from 260 per 1000 to 140 in 2005 . Nonetheless, recent data shows the region unlikely to meet this goal. According to Easterly (2009), how the goal is measured matters: “...a goal of proportional reduction is more likely to be met by initially low mortality countries, while a goal of absolute reduction in child mortality rate would more likely to be met in the initially high mortality countries. Since the goal was stated in proportional terms and Africa was the highest mortality region, the goal as stated was less likely to be met in Africa". 
Goal Number Five: Reduce by three quarters, between 1990 and 2015, the maternal mortality ratio.

Today the under-five mortality rate is 109 per 1,000 , down from 178 per 1,000 in 1990 (incidentally, the rate in Slovenia is 2.6 per 1,000). While that is a $39 \%$ decline, it is nowhere near the $75 \%$ reduction called for in goal number five and the MDG target is unlikely to be met. There are many reasons why this rate remains the highest in the world (indeed $49 \%$ of all under-five-year-old deaths occur in sub-Saharan Africa): less than half of those mothers will have access to a qualified health worker and the infant will be subject to a variety of illnesses such as diarrhea and malaria that could easily be prevented by cheap and simple medicines and bed nets.

Here the problem is also reliable data: Attaran (2005) makes the convincing point that trustworthy data, especially on maternal mortality, is scare and unreliable and thus any measurement should be take with caution.

Goal Number Six: Have halted by 2015, and begun to reverse the spread of HIV/AIDS.

Of course AIDS is the region's biggest killer (about a quarter of all deaths) followed by malaria, respiratory infections and diarrhea diseases. About five percent of Africa's population in infected by HIV/AIDS. Unfortunately not enough suffers have access to antiretroviral drugs (which can reduce mother-to-baby transmissions). As is the case elsewhere on the continent, AIDS has had a huge negative impact on productivity as it has hit the working age population worst, although tragically, many, too many, children are infected as well. Here the region is making progress as the HIV infection rate has declined by some $20 \%$ compared to 2004. Again, having the furthest to go, sub-Saharan Africa will find it difficult to reach this goal.

Goal Number Seven: Halve, by 2015, the proportion of the population without sustainable access to safe drinking water and basic sanitation.

Interestingly, again the success here depends on how the goal is measured. The region is indeed behind all other regions in reducing the percentage of its population without access to clean water, as only $61 \%$ of the population has access (compared to over $90 \%$ in Latin America). However, in fact it is doing better if the measurement were to show the percentage with access to clean water. Consider this very simple example: if a country went from one person to two people who have access to clean water, that would represent a $50 \%$ increase. However, if another country with a population of 100 people increased by one person, that would represent only a 1 percent increase. If the measurement were to increase the percentage of people with clean water then Africa would have succeeded.

The point here is that, for whatever reason, the MDG measurement tools set in 2000 has made it impossible for any country in sub-Saharan Africa, to meet them all, or indeed even most. On the other hand, much of the region has shown improvement in all areas over the past decade, especially noteworthy given the considerable constraints discussed above. 


\section{Complications of Formal vs Informal Rule}

Complicating the daunting social agenda described above is the type of governing structure in most African countries. In many states the formal and informal political orders overlap. The formal orders are the internationally recognized governments and attendant bureaucracies and trappings of a "modern" nation state. The informal order rests around the national ruler, and this is sometimes known as the neo-patrimonial state (Chabal, 2010). The patriarch derives his legitimacy from his ability to deliver to his followers. This system differs from what we know in the West where the state is there to serve all of its citizens and the well- being of the state as a whole. The rulers who have been successful in staying in power have been able to use the apparatus of the modern, formal state to deliver to the largest number of supporters.

Note that success in this context does not imply economic development nor growth, only maintenance of power. Indeed, the measure of "success" differs between those looking from the inside (did the ruler deliver the bounty to his followers?) vs those from the outside (in the terms of the criteria established by the Western governments' bureaucracies). In the past, and especially during the Cold War, viewers from the outside were fairly content if the ruler met a minimum of basic criteria and ignored the informal practices. There of course numerous examples here, including Zaire's Mobutu, Kenya's Kenyatta or Ivory Coast's Huophet-Boigny.

Nonetheless, for the long-term the mix of the informal and formal governance styles was and is not always compatible. As Chabal notes, “...neo-patrimonial governments cannot invest or promote the self-sustaining economic growth that the country requires because they need continually to spend in order to placate their clients" (Chabal, 2010).

Because of this incompatibility, country after country witnessed economic stagnation during the 1980s and 1990s. Of course there were many other causes of this stagnation: declining international terms of trade, poorly developed physical infrastructure, lack of educated workforce and a poor enabling environment for the private sector, as discussed above. Nonetheless, as economies entropied during the 1980s, rulers had to seek ever- increasing support from the international donor community. After the Cold War donor states began to impose increasing conditions on assistance. With the intense pressures from both the formal and informal support groups, corruption increased and ruling became a negative sum game where the costs of power began to outweigh the benefits. In effect, the aim of the rulers was to grab as much of the states' resources before his rivals did.

At one end of the spectrum now one finds a Somalia or a Democratic Republic of Congo where the state no longer serves an effective administrative function, i.e., a "failed state". This is where the informal takes over the formal structures of the state, and the result is the plundering of the state's resources for the ruler's purpose of maintaining power at any price. When this is in full force it results in a reinforcing downward spiral of state decline. During this period the ruling party ignores their formal duties and start to exploit the state's resources for their own gain.

Despite promising growth during the past five years, the region still faces tremendous 
obstacles in matching these governing structures, especially in deciding how to allocate their scarce resources.

\section{Conclusion}

Given the above, how will Africa's leadership make the decisions not only to meet the MDGs but to move the country forward in all important areas? To meet the MDGs the government of the average country in the region has a budget of approximately $\$ 3.62$ billion annually, equal to about $\$ 262$ per person. This of course does not include servicing debt, about $\$ 219$ million (and even this amount would be larger had it not been for significant re-scheduling and debt forgiveness during the past decade or so). If this payment is deducted then the annual funding available is closer to $\$ 240$ per person.

The UN calculated how much it would cost a sample group of African countries (Ghana, Tanzania and Uganda) to meet the MDGs (Bolton, 2012). According to that UN study, about $7 \%$ of Gross National Income per capita would have to be spent on health costs, coming to about $\$ 53$ per person (the region's average GNI per capita is about \$757). For education (mostly to achieve 100\% primary enrolment) spending would be equal to $4.5 \%$ of GNI, or $\$ 35$ per person. Infrastructure would come to $3.8 \%$ and energy $3.5 \%$, equal to $\$ 29$ and $\$ 27$ per person respectively. Other related sectors that would need to be address would include sanitation, water supply, public facilities, universities, etc which equal $6.1 \%$ of GNI, or $\$ 47$ per person. When totaled, the sum comes to nearly $\$ 200$, compared to a total budget of $\$ 262$ per person.

However, in addition to meeting the MDGs, countries in the region have other obligations to meet with the remaining $\$ 60$ per person. Military spending is much less than in other parts of the world about $2 \%$ of GNI (in the US it is closer to $4 \%$ ) but the risk of war with neighbors is high. In addition, countries continue to face natural disasters such as almost annual flooding. These countries have to maintain a legal structure, diplomatic representation abroad, sanitation, agricultural extension services, housing, transportation and a variety of normal "day to day" obligations.

Even if the leader make the right choices, is not corrupt, is efficient and instills his integrity throughout his government, it is impossible for most countries in the region to meet all of these needs given its budget, and foreign assistance (about $\$ 65$ per capita) is not sufficient to bridge the gap. Indeed, a UNDP study suggests that for a typical low income country, external financing will be required on the order of 10-20\% of GDP (UN Millennium Project, 2005).

We conclude with several questions directed to sub-Saharan Africa: If it is this difficult for an "average" country, how can the poorest countries expect to perform? Will governments be able to find a way to foster growth and obtain the resources necessary? Can African governance be improved so that this economic growth and development can really take root? Will leaders make the right choices given their almost impossible constraints? 
For this to happen we need to recognize the role and functions of the informal ruling sector and also acknowledge the incentives involved. Equally important perhaps, we need to rethink the development agenda. Today that agenda is dictated by and large by the Western donors. In the future that agenda must be driven by the realities of the combination of the mix of informal and formal governing structures. If rulers continue to commit to meeting the objectives at the formal level while at the same time prioritize the demands of the informal sector then they will not be able to escape the poverty trap and underdevelopment nor move toward true, sustained economic and social development for all of their people. Indeed, insisting on democratic systems as a prerequisite for support (as positive as that goal is in the long term), many Africans on the ground who see no change in their plight. Perhaps the recent trends in South Africa are the ultimate proof of this dilemma. Neither the Washington Consensus, NEPAP nor any other outside "solution" will work until and unless individual rulers see how any such agenda can be adapted to overcome the problem of neo-patrimonialism.

Perhaps at the end of the day what really matters is not if Africa reaches most of the MDGs since goals, while important in measuring welfare success, do not really address the more urgent need for stimulating productive and sustained economic growth that in the long term will translate into higher welfare.

\section{References}

Abrahamsen, R. (2000). Disciplinary Democracy: Development Discourse and Good Governance in Africa. London: Zed Books.

Adejumobi, Said. (2004). Democracy and Good Governance in Africa: Theoretical and Methodological Issues. Trenton, NJ: Africa World Press.

Adetula, Victor AAO. (2011). "Measuring Democracy and 'Good Governance' in Africa: A Critique of Assumptions and Methods." Governance in the 21st Century. Cape Town: HSRC, 2011. 10-25. Hsrcpress. Web.

Amoako, K. Y. (2003). The UNECA and Good Governance in Africa. Harvard International Development Conference. Web.

Attaran, A. (2005). An Immeasurable Crisis? A Criticism of the MDGs and Why They $\begin{array}{llll}\text { Cannot be } & \text { Measured. } & \text { 95oS (10), } & \text { Medicine, }\end{array}$ http://dx.doi.org/10.1371/journal.pmed.0020318

Ayogu, Melivin D. (2001). Corporate Governance in Africa: The Record and Policies for Good Governance. Afdb.org. Addb.org. Web.

Brautigam, A., \& Knack, S. (2004). Foreign Aid, Institutions and Governance in Sub-Saharan Africa. Economic Development and Cultural Change, 52(2), 255-286. http://dx.doi.org/10.1086/380592

Campbell, Bonnie. (2006). Better Resource Governance in Africa: On What Development 
Agenda? Minerals \& Energy - Raw Materials Report 21.3-4.

Chabal, P. (2010). The State of Governance in Africa. SAIIA Occasional Paper Number 26, 2010.

Clemens, M., Kenny, C., \& Moss T. (2007). The Trouble with the MDGs: Confronting Expectations of Aid and Development Success. World Development, 35(5), 735-751. http://dx.doi.org/10.1016/j.worlddev.2006.08.003

Clemens, M, Moss T \& Moss T. (2005). What's Wrong with the Millennium Development Goals? Center for Global Development Brief.

Easterly, W. (2009). How the Millennium Development Goals Are Unfair to Africa. World Development, 37(1), 26-35. http://dx.doi.org/10.1016/j.worlddev.2008.02.009

Fosu, R., Bates, R., \& Hoeffler, A. (2006). Institutions, Governance and Economic Development in Africa: An Overview. Journal of African Economies, 114, 1243-1284. http://dx.doi.org/10.1093/jae/ejk004

Haines, A. (2004). Can the Millennium Development Goals Be Attained? Bmj, 329(7462), 394-397. http://dx.doi.org/10.1136/bmj.329.7462.394

Hydén, Goran, Dele Olowu, \& H. W. O. Okoth-Ogendo. (2000). African Perspectives on Governance. Trenton, NJ: Africa World.

Kakonge, J. O. (2012). Challenges of Achieving Millennium Development Goals in Africa by 2015: Some Reflections. Global Policy, 3(2), 245-247. http://dx.doi.org/10.1111/j.1758-5899.2011.00166.x

Kruiter, A. (1996). Good Governance for Africa: Whose Governance? Maastricht: ECDPM.

Noman, Akbar. (2012). Good Growth and Governance in Africa: Rethinking Development Strategies. Oxford: Oxford UP.

Olukoshi, A. (1998). "The Elusive Prince of Denmark: Structural Adjustment and the Crisis of Governance in Africa". Nordiska Afrikainstitutet, Research Report Number 104.

Sparks, D. (2012). "Economic Trends 2012", in Africa South of the Sahara 2013. London: Rutledge.

UN Millennium Project. (2005). Investing in Development: A Practical Guide to Achieve the MDGs. UNDP.

United Nations. (2012). Millennium Development Goals Report 2012. New York: UN.

Vandemoortele, J. (2007). “The MDGs: 'M' for Misunderstood?" UN World Institute for Development Economics Research: WIDER.

World Bank. (2011). Africa Development Indicators 2011. Washington, DC: IBRD.

World Bank. (2011). Improving the Odds of Achieving the MDGs: Global Monitoring Report 2011. Washington, DC: IBRD. 
Note

Note 1 . There are 18 targets within eight goals. This paper examines only one target per goal. The eight goal, develop a global partnership for development, is not included in this analysis.

\section{Copyright Disclaimer}

Copyright reserved by the author(s).

This article is an open-access article distributed under the terms and conditions of the Creative Commons Attribution license (http://creativecommons.org/licenses/by/3.0/).

\section{Privacy Statement}

The names and E-mail addresses entered in this journal's site will be used exclusively for the purposes of this journal and will not be made available for any other purpose or to any other party. 